\title{
Foucault: contribuições da dimensão ética ao professor
}

Américo Grisotto

Professor das Faculdades Network Doutor em Educação pela UNICAMP

\section{Resumo}

Na produção filosófica de Michel Foucault é possível encontrar, no terceiro eixo de suas pesquisas, conceitos voltados para as práticas subjetivas segundo a relação que o sujeito pode manter consigo mesmo, a ponto de se constituir como obra de arte. Neste tipo de abordagem, a moral - este conjunto de regras coercitivas, que consistem em julgar ações e intenções referindo-se a valores transcendentes - sofre um "golpe" em favor da ética. Para o professor uma possibilidade se abre nesta distinção entre moral e ética, permitindo um deslocamento dos valores constituídos para a invenção de novos valores, em que a potencialização política no seu campo de trabalho pode significar uma estilização ética da sua própria existência.

Palavras-chave: Ética; Estética da existência; Professor.

\section{Résumé}

Dans la production philosophique de Michel Foucault c'est possible retrouve, dans la troisième phase de ses recherches, concepts crées sur les pratiques subjectives, c'est-à-dire, sur la relation que le sujet instaure avec lui-même, de manière à se constituer comme oeuvre de l'art. Dans ce type d'abordage, la morale - d'ensemble de règles coercitif, que consistent en juger les actions et les intentions en référence aux valeurs transcendantes, souffre un "coup" en faveur de l'éthique. Pour le professeur, ouvre une possibilité cette distinction entre morale et éthique, qui le permettre un déplacement des valeurs fixées pour l'invention de nouvelles valeurs, dont la puissance politique dans son domaine de travail passe par une stylisation éthique de l'existence elle-même.

Mots-clés: Éthique; Esthétique de l'existence; Professeur. 
O projeto de uma "ontologia crítica da atualidade” recebe, às vezes, a formulação de uma "política como ética": isso quer dizer que o interesse foucaultiano pela ética, nos anos 80, longe de ser o fim da problematização filosófica e histórica das estratégias de poder e de sua aplicação aos indivíduos, re-propõe a análise do campo político a partir da constituição ética dos sujeitos, a partir da produção da subjetividade1.

\section{A título de introdução}

$\mathrm{N}$ âmbito educacional há quem sustente, com o intuito de desenvolver a autonomia nos educandos, que os agentes escolares devem seguir orientações detalhadas com relação à formação da conduta moral. Nesta ótica estariam incluídos estudos, elaborados na maioria das vezes por especialistas das secretarias da educação que, ao explorar aspectos como "formação moral e contexto escolar”, "possibilidades e limites da escola na formação moral”, "relatos de experiências escolares de educação moral” entre outros, sugerem que ao profissional da educação caberia a tarefa e o esforço de pôr em prática tais recomendações, o que indicaria uma certa ausência da problematização da dimensão ética, própria de uma abordagem filosófica, em favor da moral.

De acordo com o documento do tema transversal ética, proposto pelos Parâmetros Curriculares Nacionais, o objetivo seria possibilitar a abertura de discussões sobre a cidadania, considerando que o contexto escolar promove um espaço privilegiado para uma educação em valores (BRASIL, 1998). Embora façam no documento a distinção filosófica entre ética e moral, os princípios valorativos, orientadores do exercício da cidadania para uma sociedade democrática, na forma como são sugeridos, justapõe ética e moral. O resultado deste procedimento seria a abertura de um espaço onde os valores, antes de serem problematizados, estariam afeitos à educação moral e até mesmo ao ensino religioso, em que, para alcançar a vida democrática, uma ética e uma cidadania, coincidentes com a moral, se instaurariam como instrumentos, em que o professor seria o principal vetor de implementação de tal proposta (GRISOTTO, 2002, p. 25).

Aliás, esta parece ser uma abordagem bem aceita há um bom tempo

${ }^{1}$ Cf. REVEL, J. Michel Foucault: conceitos essenciais. São Carlos: Claraluz, 2005, p. 46. 
no meio educacional, segundo a qual as pessoas instruídas - supostamente do lado do que seria correto propor - ofereceriam e indicariam o caminho a seguir para as pessoas que se encontram num grau menor de instrução - que não deixam de ser agentes, mas que, deixados a si mesmos, podem enveredar por trilhas suspeitas.

Neste sentido, pretendo me servir de uma das contribuições de Michel Foucault, a partir da qual se encontra uma distinção entre as abordagens moral e ética - e cujo enfoque se desloca para a constituição dos modos de existência ou estilos de vida, em que a ética, como o auxílio da estética, constitui-se em oposição à moral, e isto para pensar alguns aspectos das práticas sugeridas aos professores quando orientados quanto ao que convém que seja ensinado aos alunos.

Em contraste com a ideia de autonomia tutelada, a concepção de autonomia política que sugiro a partir de Foucault e redefinida na perspectiva ética, consiste num projeto de construção da própria existência e que implica evitar a identificação com formas, modelos, sejam eles de natureza psicológica, educacional, institucional.

Por este motivo, o processo da constituição ética, tanto para quem ensina quanto para quem aprende, se iniciaria pelo desprendimento da forma moral, em que o indivíduo se autocria, isto é, passa a existir através desta sua autocriação. Com este intuito, de marcar campos distintos para estas dimensões do agir humano pendendo mais para a ação crítica e criativa, estaria aberta a possibilidade para que os profissionais da área educativa, de modo particular nós professores, de que nos constituíssemos muito mais na avaliação do que fazemos, dizemos e valorizamos pelo modo de existência que isto implica - e aí estariam incluídas as escolhas que nos permitiriam a criação de nos mesmos e a construção de um modo próprio de educar -, em contraste aos esforços adaptativos frente às recomendações oficiais, que tendem a tornar inócuos os nossos referenciais, bem como a nossa efetiva atuação nos espaços onde trabalhamos. 


\section{Alguns elementos que compõem nossa relação com o cenário educacional}

O que chama a atenção nas discussões que temos hoje sobre o campo educacional é a constatação da crise em que ele se encontra e a iminente identificação de suas causas por parte dos especialistas.

A expectativa dos órgãos do governo é de certa "uniformidade" na aplicação das propostas, subsumindo que seja esta a demanda nos diferentes contextos da educação.

Em termos discursivos, as palavras de ordem são quase sempre as mesmas: conscientização e qualificação constante dos profissionais; melhor adequação às diretrizes propostas; treinamento em relação às novas tecnologias e aos encaminhamentos sugeridos, dentre outras de caráter mais secundário.

Neste contexto geral da educação, em que as necessárias mudanças nos sobrevêm de forma cumulativa e ostensiva, esforços são direcionados na reconstituição do equilíbrio de um determinado modelo, na eliminação do perigo em seu desarranjo, mas dificilmente verifica-se que o padrão proposto não dá mais conta das expectativas e que algo necessita ser recriado, repensado, ou que as ideias, as concepções, precisam ganhar vida. Aliás, seria possível um modelo que abarcasse todas as esperanças?

Um outro ponto diz respeito a uma antiga postura que parecia já superada, ou seja, a forte crença no poder “redentor” da educação, de um certo messianismo pedagógico, que afirma serem a mudança dos sistemas educativos e a renovação pedagógica os eixos fundamentais para a superação de todos os problemas e de todas as dificuldades que enfrentam atualmente “nossa” sociedade em acelerado processo de globalização.

Esta maneira de encarar a educação nos submete a planos mirabolantes diante dos quais tendemos frequentemente a nos ver como incapazes, pois assustados com a avalanche e a ilusão dos recursos momentâneos, deixamos de valorizar o que realmente fazemos na luta e 
envolvimento com nossos colegas de profissão, com os nossos alunos e com a comunidade.

O estranho nisto tudo é que existiria hoje uma espécie de consenso em torno do discurso sobre a urgência das reformas educacionais e em relação aos caminhos pelos quais devemos colocá-las em prática, um discurso que associa reforma à mudança, e esta ao progresso.

No entanto, algo de interessante pode ser fomentado frente às constantes propostas de reforma se nos propusermos a desmistificá-las. Teremos assim, não mais a perspectiva do que nos sobrevém de cima para baixo, mas uma iniciativa concreta, direta, mediante crises, sim, mas que na verdade, para quem enfrenta os desafios do dia-a-dia, são comuns ao movimento dos acontecimentos.

O princípio de que a ideia de reforma não possui um significado ou definição essencial permite, a nós professores, pelo contato que temos com as reais prioridades do nosso campo de trabalho, uma intervenção efetiva e criativa. Por outro lado, a crise que para um modelo gigantesco se apresenta como vertigem, como comprometimento sério de sua estrutura e sinal de que a ordem deve ser restabelecida, em situações menos abstratas parece ser um momento bastante salutar de mudança radical perante nos mesmos de modo a rever nossas práticas e nos dispor a ensaiar novas estratégias de resistência.

Neste sentido, o discurso sobre as reformas para a melhoria da qualidade da educação cai por terra por estar associado, na maioria das vezes, a um projeto político, cujos interesses não são os reais interesses dos envolvidos com o problema educacional.

Assim, caso nossa ação seja afirmativa e não se inferiorize diante destas iniciativas melhor aparelhadas e nem mesmo lhes reivindique maior assistência e atenção, insistiremos no ato educativo como ato, este sim político, sintonizado com o que realmente podemos. Afinal, o que se encontra em jogo neste processo diz respeito à nossa própria vida, à profissão que abraçamos. 
Desta maneira, comprometer-se politicamente não significa de forma alguma adotar o que convencionalmente chamam de "política”, mas tomar posição diante do que já possuímos, acreditamos e vivenciamos diariamente, ou seja, assumir a importância de nossa luta hodierna e nos firmarmos a partir de nossas pesquisas, estudos, convicções, mesmo que, às vezes, nos vejamos barrados pelos papéis pouco interessantes que as instituições nos impõem.

\section{Algumas questões aparentemente distantes e que envolvem a nós professores}

Dentre uma infinidade de possíveis definições de política, vamos considerá-la, a princípio, como uma atividade de intervenção social singular, seja ela social, ou pessoal, e que se propõe a garantir pela potência que lhe é inerente, o que deseja concretizar um grupo de pessoas, ou um indivíduo em particular.

Tal escolha se deve pelo fato de que esta maneira de abordar a questão considera a política uma atividade que faz uso de uma potência. Não necessariamente a potência de caráter físico, mas o uso de um impulso que ao se impor no interior das relações não é neutro face ao que lhe possa resistir. De outro modo, não existiriam tantas estratégias do regime constituído para tentar contê-la.

No entanto, as pessoas fazem uso pouco afirmativo desta potencialização de si mesmas para caracterizarem a dimensão política. De fato, tal abordagem lhes passa despercebida e lhes subsume que a política constitui-se apenas em dominação e opressão, consubstanciando a ideia que herdaram nesta esfera, isto é, a de que o poder representa necessariamente algo indigno, um mal, como se houvesse uma única ordem política no universo e que esta ordem fosse o único comando possível a ser seguido por todos.

Assim, por um lado, teríamos num sentido menos positivo, ruim talvez, mas muito mais usual, a política entendida como opressão, como 
algo destinado a pessoas inescrupulosas e, por outro, a ideia de política num sentido mais positivo, menos impeditivo, como força e potência crítica e criativa espalhada no tecido social e como poder próprio dos indivíduos, capaz de edificar ações em seu meio, pois nem todas as concepções consideram o poder como uma ação imposta por um grupo de pessoas sobre outro, ou de uma pessoa sobre outra, mas, num sentido mais propositivo, como a capacidade de fazer com que os membros de uma sociedade operem mudanças em nome do que acreditam, de modo que possa haver sempre uma saudável recolocação entre nós das questões que envolveriam nossas vidas e que a ineficácia de uma visão política inadequada tende a não contemplar.

Se assim for, num determinado momento do jogo político, portanto, um grupo de pessoas, ou mesmo um indivíduo, terá à sua disposição um capital de confiança na forma de poder, ou potência. E este poder, ou potência, de certa forma instaurado no corpo social, terá a função de instaurar novos modos de existência política. Esta maneira de conceber o poder, ou de conceber a política como força, ou potência - da qual não devemos nos desprender, isto é, não como forma negativa e nem aparentando indignidade - consistiria em algo que, compartilhado entre determinadas pessoas, ou exercido por elas, nos daria um retorno bastante interessante em termos das mudanças que poderíamos instaurar no nosso meio, inclusive e principalmente no meio educacional.

Porém, não nos enganemos. Há muito que fazer nesta direção. A forma democrática, tal como a conhecemos, por atribuir à maioria dos indivíduos uma condição de segunda mão e de menor exigência e para uns poucos a condição verídica, fez com que se tornasse inevitável um desinteresse quase que generalizado por esta questão. Soma-se a isto uma tendência, de influência cristã, a partir da qual o exercício do poder sobre si na inauguração de novos modos de existência e constitutivos da felicidade e da alegria não tuteladas parece entrar em contradição com a humildade, a abnegação, o desprendimento e teremos uma total indiferença para com a 
possibilidade de seu exercício como força e potência de cada grupo, ou indivíduo junto à sociedade.

Portanto, colhendo os resultados desta opção, enfrentamos na sociedade moderna problemas que nos impedem de realizar o que realmente podemos. Isto é, de alguma maneira nos separamos de nossa potência, de nosso poder, das possibilidades do exercício político como fruto de uma autarcia ética.

Totalmente contrário à perspectiva que nos torna impotentes, Foucault (1999) não entende o porquê de chegarmos a atribuir ao poder um aspecto negativo, limitador, repressivo, uma vez que o poder produz, fabrica, constrói. Para ele o poder instaura normas mais do que leis, e esta questão nos passa despercebida porque estamos obcecados pela ideia do poder como lógica absoluta daquilo que nos subjuga e oprime.

Segundo Foucault, não seria interessante opor o poder ao indivíduo, uma vez que o poder não deve ser visto como uma instância estranha ao corpo social. Não existe oposição binária entre dominantes e dominados. O poder está esparramado no tecido social.

De outro modo, a ação deste pensador francês, de acordo com Gallo (1997), dá-se como um afrontamento direto à clássica concepção do poder como aquele que se encontra concentrado, pois este se encontra como que distribuído pelo meio social e não concentrado em pontos específicos.

Em sua perspectiva seria absurdo, portanto, falarmos em poder e em um 'não-poder' como oposição ao mesmo; podemos isto sim falar em poderes múltiplos e múltiplos contrapoderes, que só se definem enquanto tal na relação de uns com os outros ${ }^{2}$ (p. 99-100).

Se de fato o poder se distribui, por que então vê-lo como algo cristalizado na figura tradicional do Estado, nas monarquias absolutas europeias, apenas nas mãos daqueles que nos representam?

Com estas pontuações, Foucault construiu elementos que o levaram a

\footnotetext{
${ }^{2}$ Grifo do autor.
} 
desmontar a matriz ordem/obediência, em que ser cidadão não significa necessariamente submeter-se, a ponto de legitimar a ideia de que algumas pessoas possuem poder e outras não.

Neste sentido, podemos dizer que este pensador, ao tematizar em seus escritos a relação poder-saber, não adentrou apenas em questões relativas ao campo da teoria política, mas nos deixou contribuições instigantes a respeito da dimensão ética, ou seja, pensamentos a respeito da sociedade que vivemos e de como cada indivíduo pode agir diante dela e de si mesmo. E isto de modo a fazer uso de sua força, potência, poder, como resistência à forma, ou força, potência, poder, que o constituiu historicamente: o uso estratégico de sua força, potência, ou poder sobre si mesmo de maneira a provocar um desvio crítico e criativo face à força, potência, ou poder vigente que o forjou.

Ao fazer a história do presente, portanto, Foucault optou por histórias que foram sempre locais e regionais. Campos em que batalhas foram travadas. E que sempre mostraram algo de transitório, de singular, de passageiro, em cada uma das figuras em que nos reconhecemos.

Assim, podemos pensar que o professor, além de ministrar e estudar o que é específico de sua área de ensino, pode diagnosticar numa política o que não permite uma ética, ou potencialização de nós mesmos e dos nossos educandos, bem como as circunstâncias do contexto em que vive e trabalha, trazendo à superfície as formas, os contornos do seu cotidiano a ponto de avaliar sua constituição, validade e vigor: a não separação entre o empenho teórico e a mais concreta demanda histórica. Isto é, identificar as implicações do político e do ético e, melhor ainda, reinventá-los, recriá-los a todo o momento como boa opção quanto ao seu envolvimento com a sociedade e com a educação especificamente.

\section{Alguns apontamentos mais específicos: a dimensão ética em Foucault}

Lançando mão de um recurso didático, que para nós professores não 
representa grande novidade, é que podemos falar de um eixo ou domínio de pesquisa na obra de Foucault que diz respeito à ética. Mas, na verdade, tal perspectiva não existe com este isolamento. Quando este nosso pensador nos remete ao tema do poder-saber, por exemplo, em que a dimensão política, epistemológica, toma a frente, não significa que não haja aí implicações éticas, estéticas, lógicas etc.

Em seu trabalho, uma temática ou mesmo duas delas podem vir à tona, como é o caso da ética e da estética em suas últimas obras, mas as demais - sobre as quais se debruçou - não estão ausentes, pelo contrário, encontram-se ali presentes e imbricadas como que flutuando ao lado, alicerçando uma opinião, implementando um raciocínio, inserindo uma perspectiva. Neste sentido, tratar da dimensão ética em Foucault implica perceber que as demais dimensões do seu pensamento filosófico encontramse a todo o momento presentes.

É certo que, diferentemente do que ocorreu nas pesquisas voltadas para relação poder-saber, Foucault, quando trata do cuidado de si, ou da relação de si para consigo, não menciona questões relativas à escola moderna ou ao modelo de educação que herdamos. Talvez neste momento, da constituição de si nas pesquisas deste pensador, não caiba mais a denúncia e a crítica da escola como instituição que se fortaleça e exista porque há consciências para serem adestradas, submetidas, afastadas do poder que possuem, mas uma outra serventia deste mesmo espaço. Provavelmente um impulso mais propositivo e livre de encontros entre pessoas com a disposição de revolucionar o meio educativo do qual participam, quando se propõem a revolucionar a si mesmas.

Provavelmente seja esta uma distinção que teríamos que subentender na leitura de sua obra quando a didatizamos, ou seja, o que a princípio se constituiu em Foucault uma atitude de desvendamento nas construções do saber e da relação poder-saber, e posteriormente compreender a possibilidade que nos oferece este autor acerca da constituição da existência como arte de viver. 
Assim, o que aparenta ser uma inflexão em seu trabalho, quando trata da ética como uma estética da existência, pode ser visto com um ato complementar e de profunda imbricação com as demais dimensões do seu pensamento, ou seja, a ideia de que a atitude revolucionária da desconstrução do instituído e da consciência consiste numa espécie de abertura dos espaços para novas formas de vida.

Justamente em suas obras sobre a História da Sexualidade e seus cursos no Collège de France sobre a Hermenêutica do Sujeito, Foucault recupera uma espécie de admiração estética do sujeito independente e dedicado a sua excelência libertadora. O cuidado e o aperfeiçoamento artístico de si, precedido do rigoroso auto-exame, não como valorização de uma época que se esvaiu, mas como via útil de uma nova realização prática. A construção e potencialização de si como estratégia.

Diante dos planos estratégicos do poder constituído de uma coletividade operando segundo uma uniformidade normalizadora, o desafio também estratégico da resistência e da constituição de si mesmo nos oferece, segundo Foucault, uma saída ética e que tem implicações na formação de uma outra ideia do que seja a política.

\section{Alguns elementos rumo a uma ética da existência: a figura do intelectual específico}

A figura do intelectual para Foucault distancia-se da figura do profeta que anuncia verdades para um futuro distante e que, com este intuito "iluminista”, se esmeraria em nos oferecer uma crítica global dos acontecimentos numa política já dada.

Segundo sua contribuição, o intelectual específico seria muito mais a figura de quem nos apresenta um diagnóstico do presente para nos situar frente ao que possa acontecer e segundo a área em que este pensador se dispõe a ter maior domínio, de modo que outras possibilidades estratégicas se abram no jogo de forças do embate político. 
Na condição de geógrafo, historiador, ambientalista, físico, médico sanitarista etc., ou no caso de nós, professores - reais envolvidos com o ato educativo - a nossa intervenção vai no sentido de fazer saber o que se passa numa determinada situação em que exercemos nossa atividade específica para que os perigos sejam identificados e se possa impedir toda espécie de manipulações e mistificações (ARTIÈRES, 2004, p. 22).

Como nos diz Foucault (1999, p. 39), diferentemente do intelectual que tradicionalmente se constituía a partir de sua posição de maldito mediante o que a sociedade burguesa lhe impunha, bem como do intelectual como o único capaz de identificar os mecanismos de exploração capitalista, o papel que lhe caberia de agora em diante não seria mais o de se posicionar um pouco à frente e um pouco ao lado para dizer a verdade muda de todos, mas de lutar contra as formas de poder no lugar, no espaço, onde ele é, ao mesmo tempo, o objeto e instrumento de um determinado poder, saber, discurso, de uma determinada consciência e verdade.

Segundo esta abordagem, Foucault foi, nos dizeres de Deleuze (1999, p. 40) “[...] o primeiro a nos ensinar alguma coisa de fundamental, tanto nos seus livros, quanto em um domínio prático: a indignidade de falar pelos outros".

Neste sentido, podemos potencializar nosso papel de professores não mais como representação de uma consciência eloquente capaz de orientar o caminho de todos os que se submetem ao nosso trabalho, mas como uma força que possui um poder bastante específico, num espaço de atuação onde a maioria tem o que dizer e oferecer à sua maneira.

Parafraseando Foucault, poderíamos dizer que a função do professor não consiste em modelar a vontade dos outros, mas mediante as análises que faz no campo que lhe diz respeito, pode reinterrogar as evidências e os postulados, abalar os costumes, os modos de fazer e de pensar, dissipar as familiaridades admitidas, retomar a medida das regras e das instituições e, a partir dessa reproblematização, na qual ele desempenha seu mister específico de intelectual, participar da formação de nova vontade política 
em que tem o seu papel de cidadão a desempenhar (ADORNO, 2004).

É fundamental que o professor tenha competência para avaliar quais são os problemas dos quais ele pode se ocupar. Seu campo de ação não se reduz apenas a um saber que se ensina didaticamente relativo a um programa a ser cumprido segundo as regras que lhe são imputadas, inclui também a contribuição do que se sabe e ensina como ajuda na formulação clara de problemas que envolvem a comunidade. Elaboração de problemas e estudos. Exposição destes problemas e possíveis equacionamentos estratégicos. Uma forma de engajamento e de crítica sugestiva da comunidade com a qual estabelece relação.

Deste modo, prioridades são estabelecidas. Certas situações merecerão mais atenção do que outras. E o que antes se perdia na confusão de ideias ganha sentido concreto e permite às pessoas critérios mais seguros de avaliação de si mesmas e de consequente ação.

O apoio dado a questões locais é um gesto político e ético "pois interrompe o processo individualizante do poder e abre a possibilidade de constituição de subjetividades no exterior dos esquemas de poder” (ADORNO, 2004, p. 49).

A partir deste momento podemos falar de um valor político da atitude ética por parte de todos os que se encontram envolvidos seriamente nas relações entre as pessoas, como é o caso do professor, esta figura que se ocupa intelectualmente e concretamente com situações de encontro direto com seus pares, alunos e comunidade.

\section{Alguns elementos em prol de uma existência estética da ética}

Tudo leva a crer que somos construídos a partir das escolhas que fazemos. Em certo sentido, isto tem sua razão de ser, no entanto, caso enveredemos por um estudo arqueológico, em termos da relação poder/saber, diante daquilo que julgamos conhecer, bem como através de um estudo genealógico, em termos morais, frente àquilo pensamos fazer e 
pensar autonomamente, é possível que cheguemos à conclusão de que não passamos de autômatos programados para determinados fins e que estes não são tão legítimos quanto imaginamos. Se a tarefa que recebemos é de viver plenamente, seria de bom grado que atentássemos para tais indicações arqueológicas e genealógicas, presentes nas obras de Foucault, de maneira que adquiríssemos um arsenal de ferramentas e artefatos que nos permitiriam um grau menor de automatismo e despotencialização no usufruto de nossas próprias vidas.

No sentido de pensar a política por outro viés, quiçá da potencialização de nós mesmos, tais questões dizem respeito à dimensão ética e - pelo que procuramos deixar claro nos tópicos anteriores, nesta nossa conversação com Foucault - encontram-se imbricadas em outras dimensões das pesquisas desenvolvidas por este pensador. Por este motivo falamos em política e acabamos desembocando na ética, falamos em ética e acabamos por mencionar questões relativas à estética e, assim, de maneira consecutiva em outros campos do pensamento filosófico.

Assim, o que Foucault parece nos recomendar em suas pesquisas sobre o tratamento de si para consigo é que as pessoas ousem construir para si uma vida bela, o que implica uma ocupação constante consigo mesmas, voltada para uma técnica do viver em que sejam possíveis outras iniciativas, inclusive e principalmente da potencialização política de si mesmas.

Como é factível perceber, esta perspectiva é a de um pacto com a própria existência como se essa se oferecesse a nós como uma matériaprima a ser modelada, estilizada, a ponto de que a potência ética e política que possuímos pudesse ser utilizada da maneira mais intensa e interessante possível. A ética em sentido político teria a serventia de nos tornar mais ativos e convictos diante das escolhas que realizamos. Em outros termos, nos muniria na fabricação e melhora artesanal de nós mesmos segundo a diferença que representamos longe de qualquer forma de regulamentação imposta.

Nas palavras do próprio Foucault (apud ESCOBAR, 1984, p. 48): 
[...] de Sócrates a Sêneca ou Plínio, por exemplo, eles não se preocupavam com a vida após a morte, que aconteceria, ou se Deus existe ou não. Este não era um grande problema para eles, o problema era qual 'techne' eu tenho que usar para viver tão bem quanto devo viver. $\mathrm{E}$ acho que uma das principais evoluções na cultura antiga tem sido que esta 'techne tou biou' se tornou mais e mais a 'techne' de si mesmo. [...] a idéia do bios como material para uma peça estética de arte é algo que me fascina. Também a idéia de que a ética pode ser uma estrutura muito forte da existência, sem qualquer relação com o jurídico por si, com um sistema autoritário, com uma estrutura disciplinar ${ }^{3}$.

Neste sentido, a ética não consistiria numa relação intrínseca com a moral ${ }^{4}$, pelo contrário, ela teria mais a ver com modos de vida que os seres humanos criaram culturalmente para si com o intuito de bem viver.

[...] um tesouro de artifícios, técnicas, ideias, procedimentos, etc... que não podem ser efetivamente reativados, mas pelo menos constituem, ou ajudam a constituir um certo ponto de vista que pode ser muito útil como uma ferramenta para analisar o que está acontecendo agora e modificá-lo (FOUCAULT apud ESCOBAR, 1984, p. 49).

Por outro lado, a ética tal e qual a vivenciamos hoje se encontra atrelada à manutenção de uma determinada estrutura econômica, social, ou política.

[...] entre a nossa ética, nossa ética pessoal, nossa vida diária e as grandes estruturas [...] há relações analíticas, e que não podemos mudar nada por exemplo, na nossa vida sexual ou nossa vida familiar, sem arruinar a nossa economia, nossa democracia, etc. Eu acho que temos que nos livrar desta ideia de uma ligação analítica entre a ética e outras estruturas (FOUCAULT apud ESCOBAR, 1984, p. 49-50).

Assim sendo, uma vez que a ética não teria necessariamente relação com as estruturas que nos engaiolam, um verdadeiro campo se abre para a liberdade de criação. Campo de fabricação muito diferente das produções

\footnotetext{
${ }^{3}$ Grifos do autor.

${ }^{4}$ Quando a distinção entre ética e moral, "enquanto a segunda diz respeito às regras coercitivas do poder e às regras facultativas da subjetivação. A ética concerne à práticas de si, ao "conduzir-se". Construir relações consigo que resistam aos códigos do saber e do poder. Criar novos estilos e princípios éticos. Além disso, a ética em Foucault não está separada da estética. Constituir modos de existência dobrando a força é fazer uma arte de viver (subjetivação).
} 
em série provenientes das linhas montagem ou de uma massa que é explorada porque pensa, age e valoriza de uma mesma maneira.

No descortino de uma história que desemboca numa uniformidade do modo de vida das pessoas, o que impressiona Foucault (1984) é o fato de que em nossa sociedade a arte tenha se tornado apenas algo relacionado a objetos e não a indivíduos, ou à vida. Para ele a vida de cada pessoa poderia se tornar uma obra de arte. Se os objetos podem se transformar em arte porque a nossa vida não?

Num mundo que se constitui a partir da ideia de trabalho como verdadeira tortura, não seria interessante, a partir destas recomendações, que nós professores uníssemos ao nosso trabalho à arte de nos constituirmos tanto ética quanto politicamente? Ou seja, por que não estender esteticamente a relação ética que temos com nós mesmos para nossa atividade política que é a educação?

Nós, professores, não nos ocupando do poder ético da constituição de nós mesmos como ato político, ou do poder que indubitavelmente possuímos - a partir do que poderia ser a reaprendizagem constante da nossa prática educativa - tendemos a nos apresentar resignados ao poder instituído. No caso de nos concentrarmos na nossa própria constituição ética e política, encerrar-se-iam, em grande parte, as submissões. E, por outro lado, se seguíssemos nos considerando ignorantes, a nossa inferioridade poderia servir de recusa à nossa imposição, sem que a marca da nossa vida se instalasse, suscitando-nos a dúvida e o enfraquecimento: será que realmente existimos? A esse respeito Nietzsche, de quem Foucault diz reiteradas vezes ter recebido uma grande influência, nos assegura, logo no início de sua III Consideração Intempestiva “Schopenhauer Educador”:

No fundo, todo homem sabe muito bem que não vive no mundo senão uma vez, na condição de único [als ein Unicum], e que nenhum acaso, por mais estranho que seja, combinará pela segunda vez uma multiplicidade tão diversa neste todo único que se é [Einerlei] (NIETZSCHE, 2003, p. 138).

Fazer com que a nossa existência valha a pena, ou que nos 
ultrapassemos sempre, talvez, inaugure em nós, envolvidos na educação, possibilidades múltiplas de que outras formas, as nossas formas de preferência, possam representar o nosso real envolvimento com a questão educacional.

Diante das prerrogativas do discurso oficial, que nos pedem seguidamente posturas de compreensão e aplicação continuadas das últimas manchetes educacionais, melhor seria que o cenário educacional fosse uma arena de conflito de forças criativas, embate de singularidades, a força vital da arte de inovar, a volta do risco crítico e criativo, da discussão e das proposições em progressão geométrica, a cogitação indefinida de quais peças outras poderiam compor o quebra-cabeça da comunidade onde nos inserimos: lugar de encontro de artistas que se pronunciam a partir de suas próprias criações e convicções no campo de uma política singular constituída como ética e estética das nossas próprias existências.

\section{Finalizando...}

Como já dissemos, diferentemente do que ocorreu nas pesquisas voltadas para relação poder-saber, Foucault quando trata do cuidado de si ou da relação de si para consigo não menciona questões relativas à escola moderna ou ao modelo de educação que herdamos, no entanto, estas ideias podem, sem embargo, ser sempre atualizadas para esta discussão. E, talvez, neste momento, em que se desvela a sugestão de que podemos nos constituir segundo novos modos de vida na constituição de nós mesmos, não caiba mais a presença da escola como instituição que se fortaleça e exista justamente porque há consciências para serem despotencializadas. E nem comporte pessoas que cumpram funções como se fossem peças num tabuleiro. Mas, que outras perspectivas mais propositivas, livres e criativas possam ser fabricadas nos encontros das pessoas com a educação num movimento de inovações políticas, estéticas, éticas. Novas possibilidades para o futuro. Ou, melhor ainda, para um futuro possível.

Nos dizeres de Nietzsche, de quem Foucault se serviu de maneira 
notável, acaso um grande pensador tenha que desprezar os homens seria a falta de empenho destes que ele desprezaria, pois é ela que dá a eles o comportamento indiferente das mercadorias fabricadas em série, indignas de contato e de ensino. O homem (o professor) que não quer pertencer à massa só precisa deixar de ser indulgente consigo mesmo, criar mais do que receber; que ele siga o que lhe grita: "Sê tu mesmo! Uma vez que tu não és isto que agora fazes, pensas e desejas” (NIETZSCHE, 2003, p. 139).

Dobrarmo-nos e nos desdobrarmos sobre nós mesmos a ponto de nos potencializarmos e nos construirmos eticamente, eis aí o desafio político presente em Foucault e não apenas no seu pensamento, mas em sua militância. Tal desafio, endereçado a nós professores, não nos alerta em outro sentido senão para o empenho e compromisso na constituição e educação de nós mesmos em favor de outras possibilidades de intervenção política e educacional, o que significa posicionar-se de forma afirmativa, crítica e criativa face à profissão que abraçamos.

\section{Referências}

ARTIÈRES, P. A ATUALIDADE: o trabalho de diagnóstico em Michel Foucault. In: In: GROS, F. (Org.); ARTIÈRES [et al.]. Foucault: a coragem da verdade. São Paulo: Parábola, 2004, 22 p.

ADORNO, F. B. A tarefa do intelectual: o modelo socrático. In: GROS, F. (Org.); ARTIÈRES [et al.]. Foucault: a coragem da verdade. São Paulo: Parábola, 2004, 21 p.

DELEUZE, G.; FOUCAULT, M. Os Intelectuais e o Poder. In: FOUCAULT, M. Ditos e escritos IV: Estratégia, Poder-Saber. Rio de Janeiro: Florence Universitária, 1999, 10 p.

FOUCAULT, M. Sobre a genealogia da Ética: uma visão do trabalho em andamento. DREYFUS, H. L. e RABINOW: entrevistas e conversas com Michel Foucault, em Berkeley, E.U.A, em abril de 1983. In: ESCOBAR, C. H. O dossier Michel Foucault. últimas entrevistas. Rio de Janeiro, 1984, 29 p.

GALLO, S. Repensar a educação: Foucault. In: GHIRALDELLI, Jr.; PRESTES N. H. Filosofia, sociedade e educaşão. Marília: Unesp, ano I, n. 1, 1997, $25 \mathrm{p}$. 
NIETZSCHE, F. Escritos sobre educação. Rio de Janeiro: PUC-Rio; São Paulo: Loyola, 2003, 227 p.

REVEL, J. Michel Foucault: conceitos essenciais. São Carlos: Claraluz, 2005, 87 p. GRISOTTO, Américo. Parâmetros curriculares nacionais: uma abordagem epistemológica das questões éticas. 2002. xi, 129 p. Dissertação (Mestrado em Educação) - Faculdade de Educação, Universidade Estadual de Campinas, Campinas. 